\title{
Green Jobs? Economic impacts of renewable energy in Germany
}

\author{
Ulrike Lehr ${ }^{1, *}$, Christian Lutz ${ }^{1}$ \\ ${ }^{1}$ Gesellschaft für Wirtschaftliche Strukturforschung mbH, Osnabrück, Germany \\ * Corresponding author. Tel: +4954140933280,Fax: +4954140933110,E-mail: lehr@gws-os.com
}

\begin{abstract}
The labor market implications of large investment into renewable energy (RE) are analyzed in this text. Although a growing RE industry can be observed in Germany the overall effect of large increases of expensive electricity and heat generating technologies on the German economy require a careful model based analysis. The paper shows the overall effects under different assumptions for fossil fuel prices, domestic installations and international trade. Most of these scenarios exhibit positive effects.
\end{abstract}

Keywords: Renewable Energy, Germany, Economic Effects

\section{Introduction}

The positive impacts of an increasing share of renewable energy (RE) on the mitigation of climate change as well as on the decrease of the dependence of energy imports are indisputable. However, such are currently still the additional costs of heat and electricity generation from most renewable energy sources (RES). For a stable economic development, the overall balance of positive and negative effects under different possible future development pathways of fossil fuel prices, global climate policies and global trade is of interest. To account for all effects in a consistent framework, a macroeconometric model is employed. Economic development is measured via the comparison of economic indicators such as GDP and employment from different simulation runs. Overall net positive effects can be seen for instance as higher employment in one simulation run compared with the other.

Additionally, the sectoral disaggregation of our model leads to a wide array of interesting results in terms of winners and losers of policies to support renewable energy. This contribution is organized as follows: This introduction is followed by section 2 on the methodology applied. The modeling framework is explained and the scenarios are described. Section 3 presents modeling results followed by a discussion. Section 4 concludes.

\section{Methodology}

\subsection{Net economic effects}

The discussion about employment effects of the increase of renewable energy often centers on so-called net employment. The rising installation of renewable energy systems in some European countries such as Germany, Denmark and Spain has intensified the discussion of costs and benefits of renewable energy systems. One suggestion is that price increases from increasing shares of renewable energy lead to job losses somewhere else in the economy and the net effects will be negative.

Production, installation, operation and maintenance of windmills, solar modules, biomass power plants or heating systems as well as biogas and solar thermal applications have a positive investment effect on the respective industries (Figure 1). Employment in these sectors increased steadily in Germany over the last years (cf. [1]) and is often referred to as gross employment. International demand for RE technologies increases employment in these sectors. The wind industry, for instance, makes up to 70\% of its 2009 turnover from exports. Hydro energy and solar modules also exhibit high export shares in their respective turnover. 


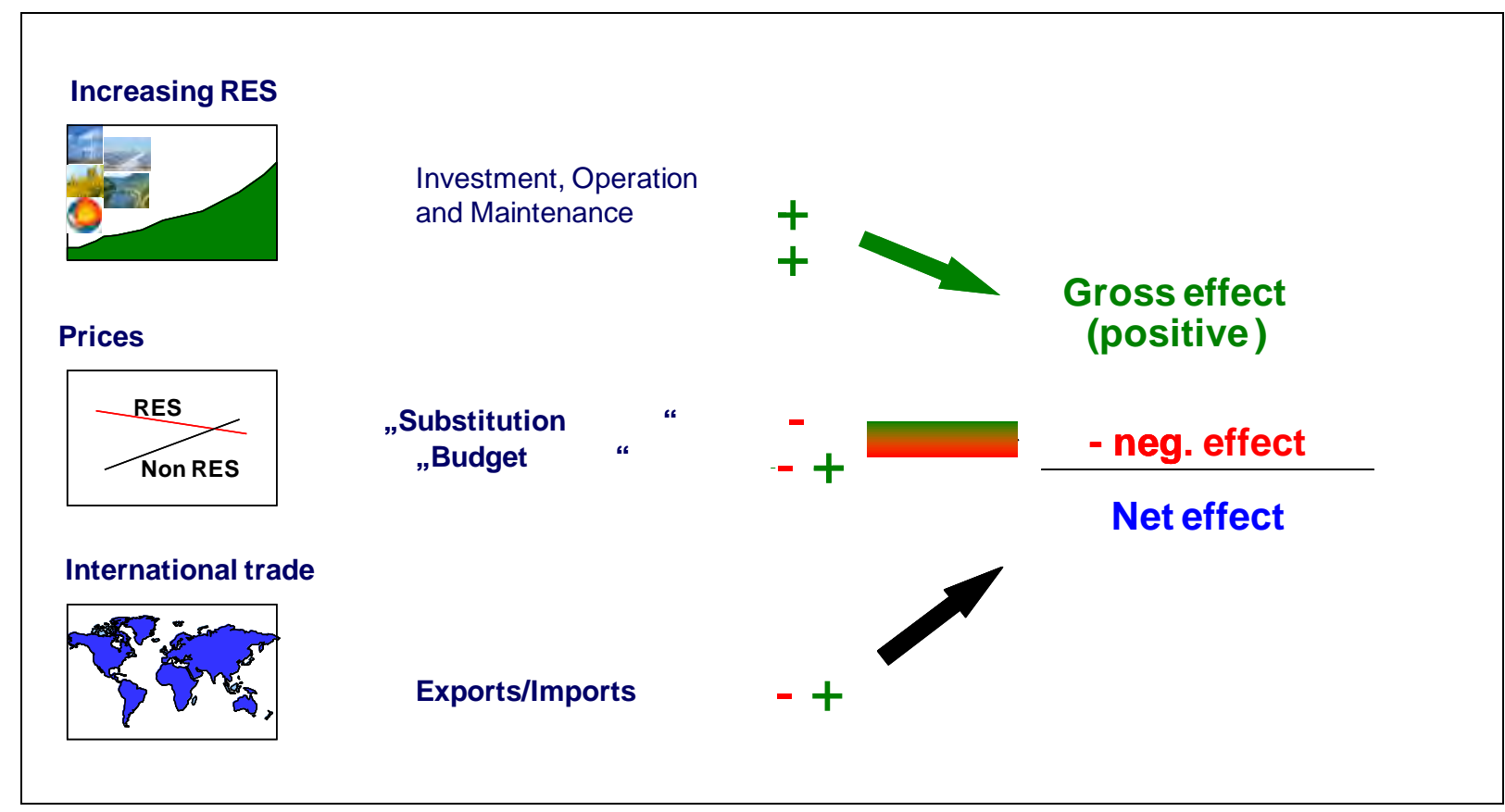

Figure 1: Economic effects of an RE increase on the labor market (cf. Staiß et al. 2006)

Negative impacts on the economy stem from 2 different sources: firstly, investment in renewable energy technologies crowds out investment in fossil fuel technologies such as coal fired power plants, oil fired heating systems and maybe at some future point gasoline driven cars. This substitution effect leads to profit losses in the respective economic sectors.

The second negative effect is larger than the substitution effect and comes from the additional costs of RE systems. Germany supports RE electricity with a feed-in tariff, which leads to electricity price increases for households and firms. This so-called budget effect (Figure 1) reduces the budget for other expenditures resulting in job losses in the respective sectors. Positive and negative impacts are multiplied and distributed through the economic system: additional employment results in additional expenditure on consumption and additional jobs in the respective sectors as well as additional taxes and therefore increases in the governmental budget. Negative impacts affect the economy through the same channels. For information on the net effects one has to employ a model of the total economy.

\subsection{Model}

The environmental macroeconometric model PANTA RHEI is at the core of our methodological approach. PANTA RHEI is an environmentally extended version (cf. [2], [3], [4], [5]) of the macro-econometric simulation and forecasting model INFORGE. It is based on official statistics and consistently describes inter-industry flows between 59 sectors. It includes consumption, government, investment, construction, inventory and exports as well as prices, wages, labor compensation, profits, taxes, etc. on the sectoral and macroeconomic level [6],[7].

The behavioral equations reflect bounded rationality rather than optimizing behavior of agents. All parameters are estimated econometrically from time series data (1991 - 2008). Producer prices are the result of mark-up calculations of firms. Output decisions follow observable historic developments, including observed inefficiencies rather than optimal choices. 
The energy module captures the dependence between economic development, energy input and $\mathrm{CO}_{2}$ emissions. It contains the full energy balance with primary energy input, transformation and final energy consumption for 20 energy consumption sectors, 27 fossil energy carriers and the satellite balance for renewable energy [8]. The energy module is fully integrated into the economic part of the model.

To examine the economic effects of increasing shares of renewable energy in Germany our analysis applies PANTA RHEI to a set of scenarios and compares the resulting economic quantities.

\subsection{Scenarios}

Scenarios, in contrast to forecasts, present consistently derived different possible future developments. They enable a "what-if” analysis. For Germany, we apply the official scenario for the development of new RE installations, the so-called "Lead Scenario [9]. This scenario includes bottom-up modeled cost-structures of RE technologies, based on the learning curves for $10 \mathrm{RE}$ technologies. It is a target oriented scenario, in which 84.7 percent RE will be reached in electricity generation, 49.4 percent in heat generation and 49.5 percent in primary energy supply. A scenario with zero investment in RE since 2000 serves as the respective (hypothetical) reference development.

The scenario technique is often applied when future development hinges on the development of some crucial quantities, whose development is highly uncertain. Future employment effects from increasing renewable energy, for instance, critically depend on the relative costs of renewable energy compared to fossil fuels, on national policies for the support of renewable energy and on international climate regimes and RE strategies.

Thus we constructed the following scenarios for the development of each of these decisive factors (cf. Table 1):

1. two different price paths for international energy prices

2. three different scenarios for the domestic investment

3. four different export scenarios, which vary by the share of imports and domestic production in 10 world regions and 10 technologies and with respect to the trade shares of Germany.

\subsubsection{International energy prices}

International energy prices determine the reference price for the additional costs of renewable energy systems in Germany, because large shares of fossil fuels are imported. The future development path of import prices for fossil fuels is highly uncertain considering the large fluctuations in the past couple of years. Therefore we implement a lower price scenario and a higher price scenario with the respective consequences for renewable energy diffusion. The price scenarios follow essentially the projections of the IEA. The higher price level coincides with the projections in the World Energy Outlook (WEO) 2009 [10]. The lower price level is lower than the more recent projections in WEO 2010, [11], but the upper price level exceeds the assumptions there. Since our analysis tries to stay on the conservative side of things, in the following we report the findings for the lower price level.

\subsubsection{Domestic investment}

Germany has experienced a boom in the installation of photovoltaic panels in 2010. While the German government annually updates its "Lead Scenario" [12] for the future development of 
electricity and heat from renewable energy, the latest update in 2009 did not include this rapid increase. Therefore, we included two more scenarios in our analysis, taking the likely PV developments into account. It turned out that the higher path of this set will even be overachieved in 2010, so that only the results of the original scenario and the highest sensitivity will be reported here.

\subsubsection{International development and exports}

Export is a major driver of the economic performance in Germany. This holds for the economy as such as well as for the sector of the production of facilities for the use of renewable energy. Earlier studies have shown [2] that net employment strongly depends on export levels. Therefore, RE technology exports have been modeled in great detail. Our analysis follows an idea developed by [13] for "green” goods. They analyze the world market for green goods and derive German export quantities from shares of traded goods in this market and shares of German producers in world trade. We follow a similar logic and determine the trade volume of renewable energy technologies for as a calibration for the projections. For this year, the trade shares of German producers can be estimated from statistical data and additional structural knowledge. For the future we develop four scenarios, all of them based on the Energy [r]evolution scenario for global installations [14].

Table 1: An overview of the most important scenario assumptions (highlighted scenarios are reported further), real prices (2005)

\begin{tabular}{llllllllll}
\hline & \multicolumn{3}{c}{2009} & \multicolumn{3}{c}{2020} & & \multicolumn{3}{c}{2030} \\
\hline 1. import prices & Oil & Gas & Coal & Oil & Gas & Coal & Oil & Gas & Coal \\
& $\$ / \mathrm{bbl}$ & $€ / \mathrm{TJ}$ & $€ / \mathrm{t}$ & $\$ / \mathrm{bbl}$ & $€ / \mathrm{TJ}$ & $€ / \mathrm{t}$ & $\$ / \mathrm{bbl}$ & $€ / \mathrm{TJ}$ & $€ / \mathrm{t}$ \\
a. high & 58 & 5,794 & 79 & 96 & 10,700 & 155 & 118 & 13,800 & 202 \\
b. Low & 58 & 5,794 & 79 & 79 & 8,400 & 123 & 94 & 10,000 & 147 \\
\hline 2. domestic & & & & \multicolumn{3}{c}{ billion $€_{5}$} \\
\multicolumn{1}{l}{ investment } & & & & & & & & &
\end{tabular}

\begin{tabular}{|c|c|c|c|}
\hline $\begin{array}{l}\text { a. lead } \\
\text { scenario }\end{array}$ & 20.4 & 15.4 & 15.1 \\
\hline b. higher PV & 20.4 & 16.0 & 14.1 \\
\hline c. high PV & 20.4 & 16.6 & 14.0 \\
\hline 3. export & \multicolumn{3}{|c|}{ billion $€$} \\
\hline a. minimum & 8.6 & 7,1 & 7,1 \\
\hline b. slow & 8.6 & 19.9 & 32.7 \\
\hline c. optimistic & 8.6 & 32.9 & 47.8 \\
\hline d. maximum & 8.6 & 41.3 & 59.1 \\
\hline BMU (2010) & & & \\
\hline
\end{tabular}

The minimum case for exports is defined by holding the volume of exports constant until 2030. This translates into a high loss of German trade shares. The maximum case is determined by holding the trade shares constant on a rapidly expanding market, which can be seen as an almost tenfold increase of export volumes. Both scenarios serve as an upper and lower boundary to the more likely developments. The optimistic scenario assumes that Germany maintains significant shares in global trade. The slower scenario can either be seen as a slowdown in German competitiveness or as a tendency to wall off markets in the future. Table 1 gives an overview of the main scenario settings. 
Instead of a business-as-usual reference run, which in many studies describes a development under which no further measures are taken [15], this study uses a zero scenario (for the same approach [16]). It describes a consistent hypothetical development in energy generation without renewable energy from 2000 onwards and includes the additional fossil power plants and heat generation plants that would then be necessary along with the associated investment. In this scenario, renewable energy makes only a very limited contribution to the heat and electricity supply, for the latter predominantly from large-scale hydropower, which was already competitive even before the Renewable Energy Sources Act came into force.

In the following analysis results will be reported for the low price path and the high domestic investment path. All export scenarios will be included in the reported results.

\section{Results}

The economic impact of an activity such as the expansion of renewable energy is assessed by comparing a simulation without the activity or economic policy measure with a simulation that includes the activity.

The zero scenario based on the low price path is now compared to a development with differing degrees of domestic investment in RE and differing export trends based on the same price path. The comparison of simulation results shows macroeconomic effects such as net employment effects which can be traced back to the different scenario assumptions.

\subsection{Net employment}

To gain an overview of selected results in all the simulation runs, the charts below show the results for net employment over time. Absolute deviations from the zero scenario with the low price path are shown. Positive values should be seen as positive net employment by comparison with a development without expansion of renewable energy. Negative values indicate that employment lags behind the value it would have had without the expansion of renewable energy.

The increase of renewable energy leads in most of the scenarios studied to positive net employment, rising steadily, particularly from 2020 onwards. The net effects are negative in the scenarios with minimal exports (i.e. remaining constant at today's level), although this should be seen here more as a notional lower limit. In this case, for the two expansion paths (Lead Scenario 2009 and PV2) lower values for employment are observed by comparison with the zero scenario. However, at the end of the observation period there is a reversal in these cases: the net employment effects become slightly positive or are neutral. The influence of exports on the domestic employment level also becomes very evident in the scenarios studied: using the optimistic expectations, the positive net employment effect rises by 2030 to values in excess of 150,000. In combination with cautious export expectations, there are less positive deviations from the zero scenario up to 2015. After that the positive employment effects of exports become apparent. 


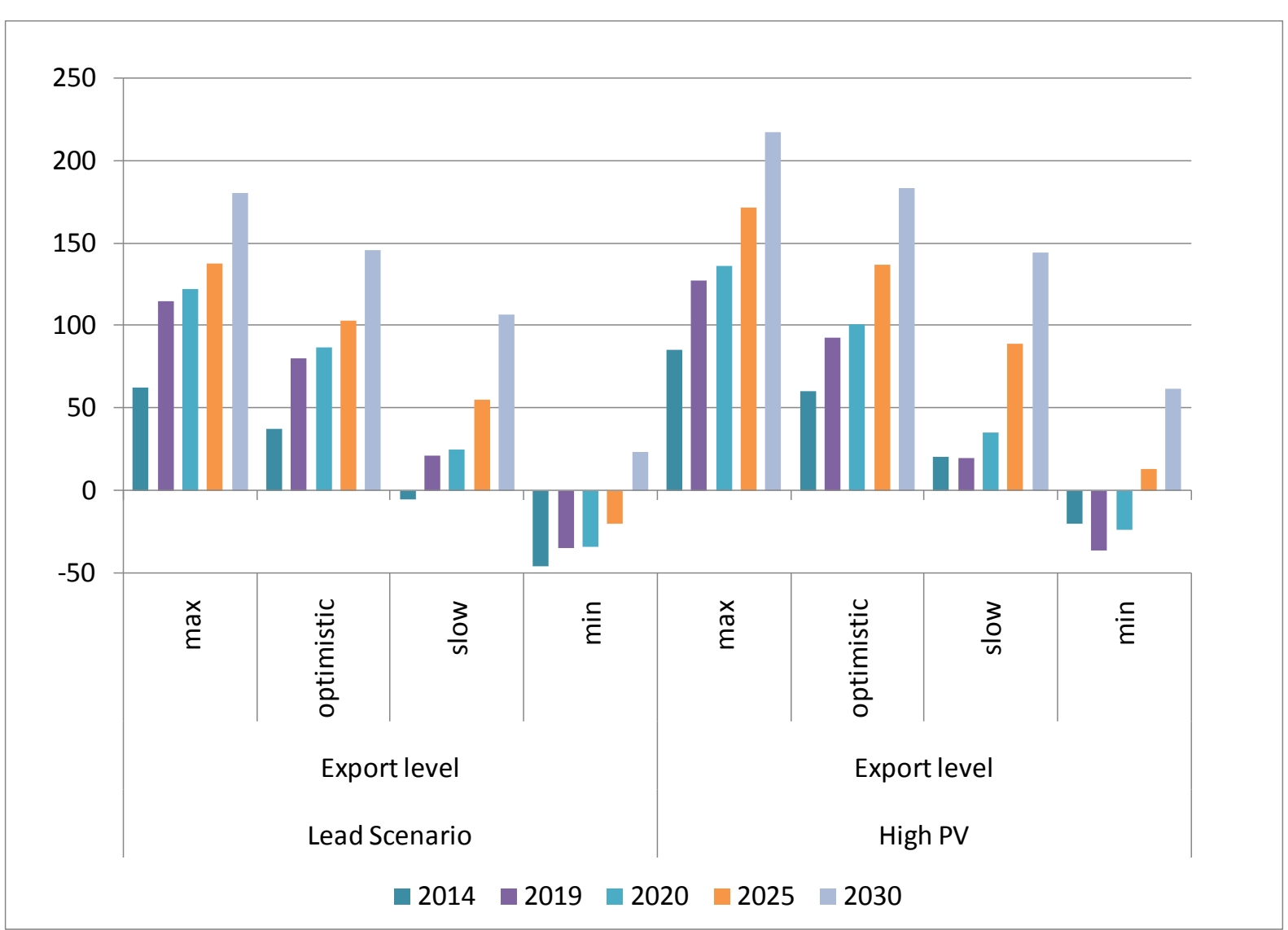

Figure 2: Employment in absolute differences to the zero scenario, in 1000 persons.

Since we are demonstrating only the low price path here, the higher additional costs, brought about by low prices for fossil energy sources, attenuate the positive net employment effects. Overall, the highest net employment stems from maximal export in combination with high PV expansion. Here net employment in 2030 is a little in excess of 200,000 people higher than it would have been without expansion of renewable energy in Germany.

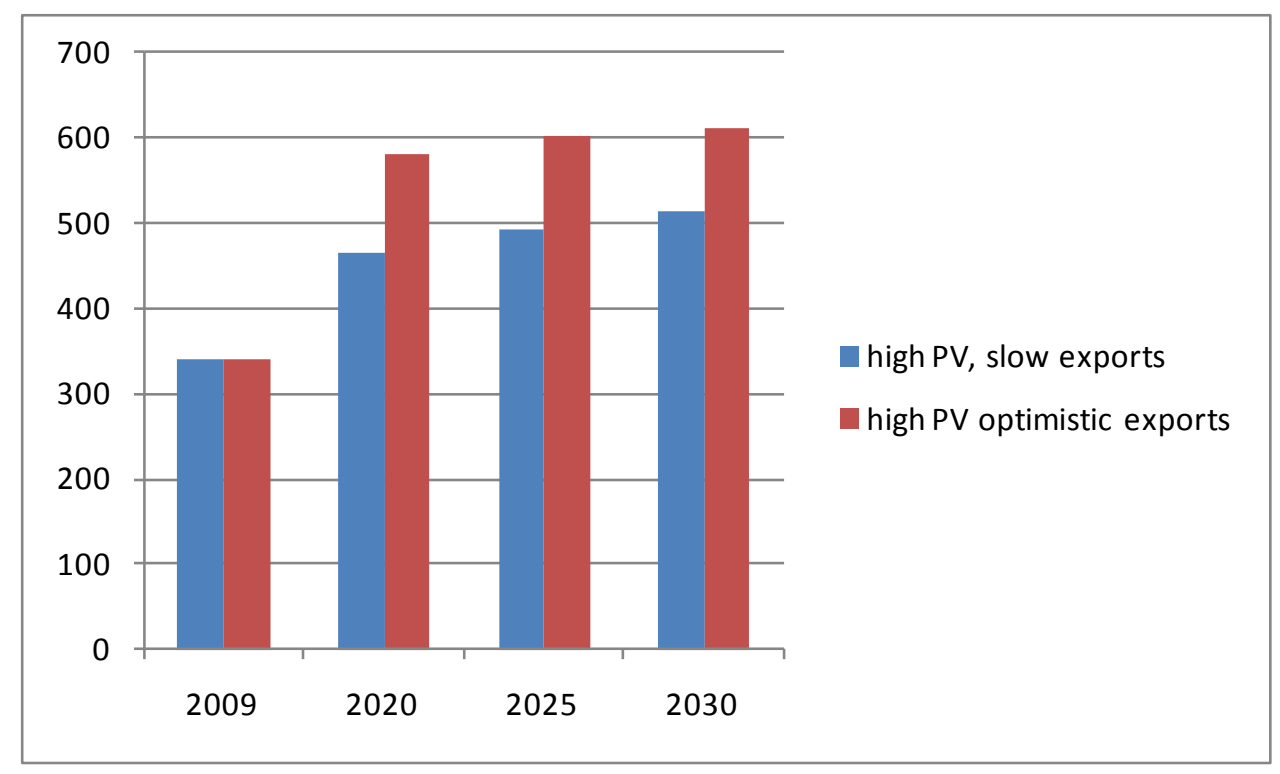

Figure 3: Gross employment in 1000 for two selected scenarios based on high domestic photovoltaic increase combined with slow (blue) or optimistic (red) exports. 
The RE industries will employ 500-600.00 people. The figure rises with firms continue to be successful on international markets. The importance of global markets can be read from Figure 3. The different assumptions about exports lead to 100.000 jobs more in the RE industry in the optimistic export scenario.

The future increases in gross employment will not be as fast as they have been in the past. In Germany, the industry doubled its employment between 2004 and 2009 [17]. 2009 339,500 people worked in the production, operation and maintenance, fuel production and input production of RE systems. Our results show a little less than twice this number by 2025.

\section{Discussion and Conclusions}

Our analysis shows possible positive impacts of the expansion of renewable energy in Germany - and the conditions and policy implication for a positive development. The literature also provides analysis with the prediction of negative impacts - for Germany and other countries. Frondel [18] calculates the additional costs of a projected increase with a national focus and claims that especially the costs of photovoltaic systems cannot be balanced. For Spain, Alvarez [19] showed negative economic impacts, only focusing on the domestic market. However, the main wind energy systems producer, Gamesa, realizes more than $90 \%$ of its turnover abroad. A sensible consideration of exports and global markets helps to understand the dynamics of countries which developed a RE industry sector.

For the EU27, the EMPLOY-RES project [20] showed slightly positive effects. The two models used in this study are either more rigid in their price adaptation or they assume perfect substitution of all factors. The PANTA RHEI approach is less rigid but does include adaptation costs as opposed to perfect substitution.

The issue of economic impacts of the expansion of renewable energy will be part of the sustainability discussion for the time to come. On the one hand, increasing installation brings down the specific costs through learning curves and scale effects. On the other hand, parity of electricity generation costs from renewables will only be reached within the next 10-15 years. The German example shows how a large domestic market leads to the development of a successful industry. However, these successes are vulnerable to abrupt policy changes, as experiences with the US industry or the Spanish market show.

\section{Acknowledgements}

This research has been supported by the German Federal Ministry for the Environment, Nature Conservation and Nuclear Safety. The full analysis includes more aspects and Dietmar Edler, Marlene O’Sullivan, Peter Bickel, Barbara Breitschopf and Joachim Nitsch contributed.

\section{References}

[1] O’Sullivan, M., Edler, D., Ottmüller, M, Lehr, U., Gross employment from renewable energy in Germany in 2009 - a first estimate, Federal Minister of the Environment, 2010.

[2] Lehr, U., Nitsch, J., Kratzat, M., Lutz, C. \& Edler, D., Renewable Energy and Employment in Germany. Energy Policy, 36, 2008, pp. 108-117.

[3] Meyer, B., Lutz, C., Schnur, P., Zika, G., Economic Policy Simulations with Global Interdependencies: A sensitivity analysis for Germany. Economic Systems Research, 19(1), 2007, p. 37-55. 
[4] Lutz, C., Meyer, B., Nathani, C., Schleich, J., Endogenous innovation, economy and environment: impacts of a technology based modelling approach for energy-intensive industries in Germany. Energy Studies Review, 15(1), 200, pp. 72-18.

[5] Lutz, C., Meyer, B., Nathani, C., Schleich, J., Endogenous technological change and emissions: The case of the German steel industry. Energy Policy, 33 (9), 2005, pp. 11431154.

[6] Meyer, B., Distelkamp, M., Wolter, M.I., Material Efficiency and EconomicEnvironmental Sustainability. Results of Simulations for Germany with the Model PANTA RHEI, Ecological Economics, 63(1), 2007, pp. 192-200.

[7] Ahlert, G., Distelkamp, M., Lutz, C., Meyer, B., Mönnig, A. \& Wolter, M.I.,. Das IAB/INFORGE-Modell. In: Schnur, P. \& Zika, G. [Eds.]: Das IAB/INFORGE-Modell. Ein sektorales makroökonometrisches Projektions- und Simulationsmodell zur Vorausschätzung des längerfristigen Arbeitskräftebedarfs. IAB-Bibliothek 318, Nürnberg, 2009, pp. 15-175.

[8] Arbeitsgemeinschaft Energiebilanzen, Energiebilanzen für die Bundesrepublik Deutschland, Satellitenbilanz „Erneuerbare Energien“ 2010.

[9] Nitsch, J. and Wenzel, B., Entwicklung der EEG-Vergütungen, EEG-Differenzkosten und der EEG-Umlage bis zum Jahr 2030 auf Basis des Leitszenario 2010, Federal Minister for the Environment, 2010.

[10] IEA (2009): International Energy Agency. World Energy Outlook 2009. Paris.

[11] IEA (2010): International Energy Agency. Energy Technology Perspectives 2010. Paris.

[12] Nitsch, J. and Wenzel, B., Lead Study 2009, Federal Minister for the Environment, 2009

[13]Edler, D. And Blazejczak, Wirtschaftsfaktor Umweltschutz, 2007.

[14] Krewitt (2008): Krewitt, W., Teske, S., Pregger, T., Naegler, T., Simon, S., Graus, W., Blomen, E. et al. "Energy (R)evolution - a Sustainable World Energy Outlook." Study commissioned by Greenpeace Int. and the European Renewable Energy Council (EREC); DLR Stuttgart, Ecofys Utrecht, 2nd edition 2008.

[15] Prognos/EWI/GWS, Energieszenarien für ein Energiekonzept der Bundesregierung. Study commissioned by the Federal Ministry of Economics and Technology (BMWi), 2010.

[16] Kratzat, M., Lehr, U., Nitsch, J., Edler, D., Lutz, C., Erneuerbare Energien: Arbeitsplatzeffekte 2006, Final report, Federal Minister for the Environment, 2007.

[17] O’Sullivan, M., Edler, D., Ottmüller, M, Lehr, U., Nienhaus, K., Breitschopf, B., Bickel, P., Khoroshun, O., Renewable employed!, Federal Minister of the Environment, 2010

[18] Frondel (2010): Frondel, M., Ritter, N., Schmidt, C. and Vance., C. Economic Impacts from the Promotion of Renewable Energy Technologies: The German Experience, study supported by Institute for Energy-Research

[19] Alvarez, G. 2009, Study of the effects on employment of public aid to renewable energy sources, Study supported by Institute for Energy-Research.

[20]ISI (2009): ISI, Ecofys, EEG, Rütter + Partner Socioeconomic Research + Consulting, LEI, SEURECO. EMPLOY-RES - Employment and growth impacts of sustainable energies in the European Union, Karlsruhe. 